\title{
Effect of red mold rice on antifatigue and exercise-related changes in lipid peroxidation in endurance exercise
}

Received: 15 April 2005 / Revised: 26 May 2005 / Accepted: 30 May 2005 / Published online: 28 June 2005

(C) Springer-Verlag 2005

\begin{abstract}
This study evaluated the effect of red mold rice supplementation on antifatigue and exercise-related changes in lipid peroxidation of male adult Wistar rats through swimming exercise. Thirty 16 -week-old rats were studied by dividing them into three groups (ten for each group). Other than the control group (CD), the other two groups were divided into a high-dose (HD) treatment group (5 $\mathrm{g}$ red mold rice/ $\mathrm{kg}$ body weight for the HD group), and a low-dose (LD) group (1 $\mathrm{g}$ red mold rice/kg body weight for the LD group). Swimming endurance tests were conducted after 28 days of red mold rice supplementation, and the result showed that the treatment group showed a higher exercise time $(\mathrm{CD}, 78.0 \pm 6.4$; LD, 104.2 \pm 9.6 ; and HD, $129.4 \pm 10.9 \mathrm{~min} ; p<0.05)$ and a higher blood glucose concentration $(\mathrm{CD}, 76.67 \pm 8.08 ; \mathrm{LD}, 111.34 \pm 8.50$; and $\mathrm{HD}, 117.67 \pm 11.06 \mathrm{mg} / \mathrm{dl} ; p<0.05)$ than the CD. Moreover, the blood lactate $(\mathrm{CD}, 45.00 \pm 0.90 ; \mathrm{LD}, 31.41 \pm 1.80$; and $\mathrm{HD}, 28.89 \pm 1.62 \mathrm{mg} / \mathrm{dl} ; p<0.05)$, blood urea nitrogen

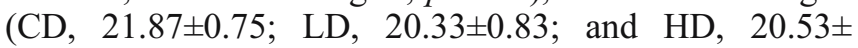
$1.09 \mathrm{mg} / \mathrm{dl} ; p<0.05)$, and hemoglobin $(\mathrm{CD}, 14.20 \pm 0.21$; $\mathrm{LD}, 13.70 \pm 0.55$; and $\mathrm{HD}, 13.28 \pm 0.35 \mathrm{~g} / \mathrm{dl} ; p<0.05)$ were also significantly lower than those of the $\mathrm{CD}$. Besides, the result suggested that the red mold rice supplementation may decrease the contribution of exercise-induced oxidative stress and improve the physiological condition of the rats.
\end{abstract}

\footnotetext{
J.-J. Wang · M.-J. Shieh · S.-L. Kuo

Department of Biotechnology,

Tajen Institute of Technology,

Ping Tung, Taiwan

C.-L. Lee · T.-M. Pan $(\bowtie)$

Institute of Microbiology and Biochemistry,

National Taiwan University,

No. 1, Sec. 4, Roosevelt Road,

Taipei, 10617, Taiwan

e-mail: tmpan@ntu.edu.tw

Tel.: +886-2-23630231

Fax: +886-2-23627044
}

\section{Introduction}

Everybody may be fatigued at any time. Fatigue is a kind of warning that lets one know that the health and mind of one's body are about or already subjected to harm, and this physiological condition is worthy of our attention. As everyone knows, other than affected physiological condition, the manifestation of fatigue and exercise is also clearly affected by food and beverage. Many researches have indicated that food can provide energy during exercise. For example, carbohydrates (glucose, fructose, glucose polymer, and corn starch), fatty acid, protein, amino acid, etc., were helpful on extensive exercise. Past researches on many endurance exercises indicated that the concentration of blood lactate increases rapidly just before exhaustion and was stored in the muscle or in the blood and caused the so-called acidosis (Putman et al. 1993; Gobatto et al. 2001). In addition, when exercise begins, the blood sugar concentration will temporarily increase then gradually decrease until it is exhausted completely. At the same time, the decrease of blood glucose concentration will suppress the functioning of the central nervous system and, in turn, decrease the continual exercising ability. This phenomenon is termed as "the production of materialized fatigue condition." Therefore, maintaining the glucose homeostasis within the body and reducing lactate degradation would enhance exercise ability (Abe et al. 1995).

Oxygen free radical was believed to have something to do with the sickness and aging of humankind. During the metabolism process of a normal person, one can produce many reactive oxygen species (ROS), and the toxic product would gradually accumulate on the cell and the tissue, which causes irreversible oxidized damage. Besides, strenuous exercise caused oxidative stress to the body and resulted in tissue damage (Armstrong 1990). During exercise, a large amount of oxygen was consumed, and the rate of oxygen-free-radical generation was accelerated due to the electron transport chain activity (Kanter 1994). Also, earlier studies showed that lipid peroxidation was increased after physical exercise (Davies et al. 1982; Alessio and Goldfarb 1988). Lipid peroxidation was frequently used as 
an indication of tissue oxidative stress as a result of a free radical attacking the cell membrane (Cho and Choi 1994).

Red mold rice has been used on food and folk medicine for thousands of years in Asian nations (Juzlova et al. 1996). The traditional method of making red mold rice was to ferment the Monascus spp. naturally on the bed of cooked, nonglutinous whole rice kernels (Lucas et al. 1993). There are many constituents in the natural product, including pigment, fatty acids, and polyketides (monacolin K) (Martinkova et al. 1995). Therefore, red mold rice is an important ingredient in fermentation food. On the other hand, secondary metabolic products of Monascus species became the key research topic in recent years. This includes Monascus pigments (red, orange, and yellow pigments) (Su and Huang 1976; Blanc et al. 1994), antibacterial activity substances (Wong and Koehler 1981), cholesterol synthetic inhibitor-monacolin K (Endo 1979), antihypertensive substances- $\gamma$-aminobutyric acid (GABA) (Kono and Himeno 2000), antioxidant action (Anyia et al. 1999, 2000), antitumor promotion action (Yasukawa et al. 1994), and immunosuppressive action (Martinkova et al. 1999). Among all of the materials mentioned above, the species that lead to antioxidant action and antitumor cure of monacolin $\mathrm{K}$ has been drawing the attention of researchers (Jeon et al. 2001; Zhou and Kummerow 2000). The antioxidant activity of Monascus species had been suggested by Anyia et al. $(1999,2000)$ and verified in our previous studies (Wang et al., unpublished data).

Since red mold rice possesses the ability to lower cholesterol level and blood pressure, it has been developed into functional health food for a human dietary supplement marketed in the United States (Cholestin; Pharmanex, Redwood City, CA, USA). More and more research indicated that daily intake of the designated food product can actually contribute to the prevention or treatment of chronic illness. The functional food products that contained a physiological activated substance were doubly valued by various social circles and drew much attention from current Taiwanese and world food scientific researchers. Hopefully, the medical cost can be effectively lowered by regulating the food and beverage intake of humans.

This research was developed based on the latest application of a red mold rice product. For this reason, the product, obtained after solid-state fermentation of Monascus spp., was used as a rat diet supplement to investigate the lipid peroxidation effect on antifatigue and endurance exercise.

\section{Materials and methods}

Microorganism and seed cultures

The screening for red mold rice production was carried using Monascus purpureus NTU 803. M. purpureus NTU 803 possesses the ability to produce monacolin K, GABA, and pigments. Our research work team had completed a series of research works using $M$. purpureus NTU 803 (Wang and Pan 2003; Wang et al., unpublished data).
Therefore, the purpose of this study was to find if $M$. purpureus NTU 803 possesses other functions that could improve health. This was why we chose M. purpureus NTU 803 as the target strain in this research. The microorganisms were maintained on potato dextrose agar (PDA) slanted at $10^{\circ} \mathrm{C}$ and transferred monthly. Seed cultures were prepared by transferring a loopful of spore from the PDA slanted into a 500-ml Hinton flask containing $100 \mathrm{ml}$ of basal medium ( $100 \mathrm{~g}$ of dextrose, $10 \mathrm{~g}$ of peptone, $2 \mathrm{~g}$ of $\mathrm{KNO}_{3}, 2 \mathrm{~g}$ of $\mathrm{NH}_{4} \mathrm{H}_{2} \mathrm{PO}_{4}, 0.5 \mathrm{~g}$ of $\mathrm{MgSO}_{4} 7 \mathrm{H}_{2} \mathrm{O}$, and $0.1 \mathrm{~g}$ of $\mathrm{CaCl}_{2}$ made up in $1,000 \mathrm{ml}$ of distilled water; $\mathrm{pH}$ 6.0). The cultures were incubated at $30^{\circ} \mathrm{C}$ for $48 \mathrm{~h}$ at $110 \mathrm{rpm}$. After that, $5 \%$ inoculum was transferred for solidstate fermentation.

Solid-state fermentation and red mold rice preparation

The red mold rice preparation method had been proposed in our previous studies (Wang and Pan 2003). Long-grain rice was purchased from a local supermarket and was used as the substrate for red mold rice production under solidstate cultivation. Five hundred grams of long-grain rice was soaked in distilled water for $8 \mathrm{~h}$. After that, excess water was removed with a sieve. The soaked rice was autoclaved for $20 \mathrm{~min}$ at $121^{\circ} \mathrm{C}$ in a "koji-dish" (the koji-dish is made of wood with a dimension of $30 \times 20 \times 5 \mathrm{~cm}$ ). After being cooled, the substrate was inoculated with a $5 \%(\mathrm{v} / \mathrm{w})$ spore suspension of $M$. purpureus NTU 803, and the inoculated substrate was cultivated at $30^{\circ} \mathrm{C}$ for 10 days. The dried rice was then mechanically crushed into powder and was called red mold rice and used as a supplement to the basal diet.

\section{Animals}

Male Wistar rats aged 16 weeks were obtained from the National Laboratory Animal Breeding and Research Center located in Taipei. The experiments were carried out in a qualified animal breeding room in the animal center at our institute. (Protocol complied with guidelines described in the "Animal Protection Law," amended on Jan. 17, 2001, Hua-Zong-(1)-Yi-Tzi-9000007530, Council of Agriculture, Executive Yuan, Taiwan, ROC.). Thirty Wistar rats were divided at random into three treatment groups, with ten rats per group, and were placed on one of the following three dietary treatments: basal diet [control group (CD)] (commercial diet, Fwusow Industry Co., Ltd., Taiwan, ROC) and basal diet supplemented with red mold rice. The red mold rice was first dissolved in distilled water, and the distilled water was then fed into the rat by force. The treatment groups were gavaged with two different doses of red mold rice, $5 \mathrm{~g}$ red mold rice $/ \mathrm{kg}$ body weight for the high-dose (HD) group and $1 \mathrm{~g}$ red mold rice $/ \mathrm{kg}$ body weight for the low-dose (LD) group. The rats were housed at random in cages with two rats per cage. Ad libitum food and water was provided throughout the entire experimental period to make sure each rat ate a certain amount of red mold rice. The red mold rice was first 
dissolved in distilled water, and the distilled water was then fed into the rat by force (gavaged). This can ensure that each rat takes a certain amount of red mold rice and reduce the experimental error.

\section{Antifatigue activity}

During the 28 days of gavage, control animals were given normal saline and forced feeding. Antifatigue effects were assessed $10 \mathrm{~h}$ after the final sample was administered. The apparatus used in this test was an acrylic plastic pool $(90 \times 60 \times 60 \mathrm{~cm})$ filled with water maintained at $28 \pm 1^{\circ} \mathrm{C}$. The water in the acrylic plastic pool was $40 \mathrm{~cm}$ deep. Rats were allowed to swim in the water, and the endurance was defined as the time they kept swimming actively until the hind legs stopped moving for at least $10 \mathrm{~s}$ (Abe et al. 1995).

Serum preparation for glucose, lactate, blood urea nitrogen, and hemoglobin analyses

Blood samples were collected from the veins on the tails of individual mice, and the glucose, lactate, blood urea nitrogen (BUN), and hemoglobin concentrations were determined using a commercial diagnostic kit provided by Cobas Mira (Roche Diagnostic Systems Inc., Montclair, NJ, USA).

\section{Swimming exercise on lipid peroxidation}

Serum lipid peroxidation was measured by using three different methods. These included conjugated diene (DC), thiobarbituric-acid-reactive substances (TBARS), and superoxide dismutase (SOD). The DC compounds were extracted from serum samples by using chloroform/methanol (2:1), dried under a nitrogen atmosphere, and then dissolved in cyclohexane. The sample was analyzed spectrophotometrically at $232 \mathrm{~nm}$ (Corongiu et al. 1983). The TBARS were monitored according to the procedure described by Bird and Draper (1984). 1,1,3,3-tetramethoxypropane was used as the standard. The supernatant absorbance was read at $535 \mathrm{~nm}$. The SOD activity was analyzed based on the method proposed by Paglia and Valentine (1967). The values were expressed in terms of $U$ $\mathrm{SOD} / \mathrm{g} \mathrm{Hb}$. One unit of SOD is defined as $50 \%$ inhibition of the rate of reduction of 2-(4-iodophenyl)-3-(4-nitrophenol)-5-phenyltetrazolium chloride under the conditions of the assay.

\section{Amino acid analyses}

Amino acid concentrations were determined as in Kono and Himeno (2000). Mature red mold rice (5 g) was soaked in $40 \mathrm{ml} 60 \%$ ethanol solution at $25^{\circ} \mathrm{C}$ for $24 \mathrm{~h}$. After filtration $(0.45 \mu \mathrm{m})$, the filtrate was analyzed using a
Beckman 6300 amino acid analyzer (column: spherical cation-exchange resin $10 \mathrm{~cm}$, Lithium column PN 338051).

Statistical analyses

All the data were expressed as means $\pm \mathrm{SD}$, and analysis of variance (ANOVA) was used. The significance level of the statistical analyses was set at $p<0.05$. These analyses were accomplished by using statistical analyses configured for the computer (SPSS, Release 9.0, SPSS Inc., Chicago, IL, USA).

\section{Results}

Effect of red mold rice on the body weight of Wistar rats

Table 1 showed the body weight change of the rats during the experimental period. The weights of the rats were measured after they were gavaged by different dosages of red mold rice for 28 days. For the $C D$ group, the body weight at day 0 and day 28 were $427.3 \pm 30.1$ and $491.4 \pm$ $33.4 \mathrm{~g}$, respectively. For the LD groups, the body weights at day 0 and day 28 were $421.1 \pm 32.9$ and $477.1 \pm 41.2 \mathrm{~g}$, respectively. For the HD groups, the body weights at day 0 and day 28 were $435.2 \pm 33.3$ and $486.2 \pm 40.3 \mathrm{~g}$, respectively. Although the weight of the treatment groups was found to be lower than that of the $\mathrm{CD}$, the results showed that red mold rice had no significant effect on body weight.

\section{Swimming endurance test}

The maximum swimming time of the rats was measured to investigate the effect of red mold rice on antifatigue activity. Table 1 showed that the swimming time of each treatment group (LD and HD) increased significantly $(p<0.05)$ when compared with that of the $\mathrm{CD}$ group. The results indicated that the swimming time of the LD and HD groups increased by 33.59 and $65.90 \%$, respectively.

Table 1 Effect of the gavage-administered red mold rice on the body weight and swimming time of rats

\begin{tabular}{llll}
\hline Groups & Body weight & \multicolumn{2}{l}{$\begin{array}{l}\text { Swimming time } \\
\text { (min) }\end{array}$} \\
\cline { 2 - 3 } & $\begin{array}{l}\text { Before experiment } \\
\text { (day 0) }\end{array}$ & $\begin{array}{l}\text { After experiment } \\
\text { (day 28) }\end{array}$ & \\
\hline CD & $427.3 \pm 30.1^{\mathrm{a}}$ & $491.4 \pm 33.4^{\mathrm{a}}$ & $78.0 \pm 6.4^{\mathrm{a}}$ \\
$\mathrm{LD}$ & $421.1 \pm 32.9^{\mathrm{a}}$ & $477.1 \pm 41.2^{\mathrm{a}}$ & $104.2 \pm 9.6^{\mathrm{b}}$ \\
$\mathrm{HD}$ & $435.2 \pm 33.3^{\mathrm{a}}$ & $486.2 \pm 40.3^{\mathrm{a}}$ & $129.4 \pm 10.9^{\mathrm{c}}$ \\
\hline
\end{tabular}

Values are mean \pm SD of ten rats per group. For values with different superscripts, mean is significantly different among groups $(p<0.05)$ 
Serum glucose, lactate, BUN, and hemoglobin concentration

The glucose, lactate, BUN, and hemoglobin concentrations in the blood of rats with regard to different concentrations of red mold rice in the diet were measured. The measurements were conducted before and after swimming, and the results were shown in Table 2. It was found that the blood glucose concentration of each group had no significant difference $(p>0.05)$ before swimming. However, after swimming, the blood glucose of the $\mathrm{CD}, \mathrm{LD}$, and HD groups were found to be $76.67 \pm 8.08,111.33 \pm 8.50$, and $117.67 \pm 11.06 \mathrm{mg} / \mathrm{dl}$, respectively. The decrease ratios of the blood glucose of the LD (7.48\%) and HD (3.02\%) groups were lower than that of the CD group (38.17\%) $(p<0.05)$.

The concentration of blood lactate among all the groups before the swimming exercise was not significantly different $(p>0.05)$. After swimming, the concentration of blood lactate for the $\mathrm{CD}, \mathrm{LD}$, and $\mathrm{HD}$ groups was found to be $45.00 \pm 0.90,31.41 \pm 1.80$ and $28.89 \pm 1.62 \mathrm{mg} / \mathrm{dl}$, respectively, and showed significant differences $(p<0.05)$. The increase ratios of the blood lactate of the LD and HD groups were 13.31 and $4.56 \%$, respectively, which were lower than the increase ratio of $52.44 \%$ achieved by CD group. Judging from the increase ratio of blood lactate concentration, it can be seen that the treatment groups did possess the ability to retard and lower the blood lactate produced after exercise.

The BUN changes before and after swimming for all the three groups were shown in Table 2. The result showed that the BUN change was significant for all three groups $(p<0.05)$. However, judging from the BUN's rate of rising after swimming for each group, it was clear that red mold rice possessed the ability to lower or retard the formation of BUN after exercise.

The concentration of hemoglobin in the blood before and after exercise was also shown in Table 2. It could be seen that the difference among the hemoglobin concentration of each group before swimming was not significant. However, the hemoglobin concentration of the treatment groups was significantly lower than that of the control group after exercise.
Table 3 Amino acid composition of red mold rice

\begin{tabular}{lcc}
\hline Amino acid & Composition (\%) & $\begin{array}{l}\text { Concentration } \\
(\mu \mathrm{mole} / \mathrm{g})\end{array}$ \\
\hline Aspartic acid & 7.49 & 4.89 \\
Serine & 5.38 & 2.48 \\
Glutamic acid & 16.09 & 10.93 \\
Glutamine & 12.84 & 10.88 \\
Glycine & 2.06 & 0.74 \\
Alanine & 15.85 & 7.44 \\
Cystine & 3.22 & 1.85 \\
GABA & 16.12 & 5.27 \\
Ornithine & 2.95 & 1.03 \\
Lysine & 2.87 & 1.32 \\
Other & 15.13 & - \\
\hline
\end{tabular}

Effect of amino acid component in the red mold rice on the endurance of exercise

An amino acid analyzer was used to analyze red mold rice, and the result was shown in Table 3. As can be seen from Table 3 , ten types of amino acids, including alanine, aspartic acid, cystine, GABA, glutamine, glutamic acid, glycine, lysine, ornithine, and serine, constituted $84.87 \%$ of the total amino acids in the red mold rice.

\section{Lipid peroxidation in the endurance test during exercise}

The concentration change of DC, malondialdehyde (MDA), and SOD, which are the metabolism products due to lipid peroxidation after exercise, are described as follows:

Diene conjugation The conjugated double alkene is the initial-stage product of lipid peroxide. As indicated in Table 4, the DC values of the three groups did not differ significantly before swimming ( $p>0.05)$. Nevertheless, the DC values of the three groups appeared to be significantly different $(p<0.05)$, with the treatment groups exhibiting relatively lower DC values. Thus, it showed that red mold rice did have the ability to reduce the formation of the initial-stage products due to lipid peroxidation caused by exercise.

Malondialdehyde MDA is one of the final-stage byproducts of lipid peroxidation. When it reacted with TBA, a red compound named MDA-TBA (TBARS) would be pro-

Table 2 Concentration of glucose, lactate, BUN, and hemoglobin before and after maximal swimming exercise

\begin{tabular}{|c|c|c|c|c|c|c|c|c|}
\hline \multirow[t]{2}{*}{ Group } & \multicolumn{2}{|l|}{ Glucose (mg/dl) } & \multicolumn{2}{|l|}{ Lactate (mg/dl) } & \multicolumn{2}{|l|}{ BUN (mg/dl) } & \multicolumn{2}{|c|}{ Hemoglobin (g/dl) } \\
\hline & Before exercise & After exercise & Before exercise & After exercise & Before exercise & After exercise & Before exercise & After exercise \\
\hline CD & $124.00 \pm 13.08^{\mathrm{a}}$ & $76.67 \pm 8.08^{\mathrm{a}}$ & $29.52 \pm 1.44^{\mathrm{a}}$ & $45.00 \pm 0.90^{\mathrm{a}}$ & $16.37 \pm 1.02^{\mathrm{a}}$ & $21.87 \pm 0.75^{\mathrm{a}}$ & $15.80 \pm 0.55^{\mathrm{a}}$ & $14.20 \pm 0.21^{\mathrm{a}}$ \\
\hline LD & $120.33 \pm 4.62^{\mathrm{a}}$ & $111.33 \pm 8.50^{\mathrm{b}}$ & $27.72 \pm 0.99^{\mathrm{a}}$ & $31.41 \pm 1.80^{\mathrm{b}}$ & $17.26 \pm 0.81^{\mathrm{a}, \mathrm{b}}$ & $20.33 \pm 0.83^{\mathrm{b}}$ & $15.64 \pm 0.34^{\mathrm{a}}$ & $13.70 \pm 0.55^{\mathrm{a}, \mathrm{b}}$ \\
\hline HD & $121.33 \pm 10.50^{\mathrm{a}}$ & $117.67 \pm 11.06^{\mathrm{b}}$ & $27.63 \pm 1.17^{\mathrm{a}}$ & $28.89 \pm 1.62^{\mathrm{c}}$ & $17.74 \pm 0.91^{\mathrm{b}}$ & $20.53 \pm 1.09^{\mathrm{b}}$ & $15.31 \pm 0.38^{\mathrm{a}}$ & $13.28 \pm 0.35^{\mathrm{b}}$ \\
\hline
\end{tabular}

Values are mean \pm SD of ten rats per group. Values with different superscripts are significantly different at $p<0.05$ 
Table 4 Concentration of conjugated dienes, TBARS, and SOD before and after maximal swimming exercise

\begin{tabular}{|c|c|c|c|c|c|c|}
\hline \multirow[t]{2}{*}{ Groups } & \multicolumn{2}{|c|}{ Conjugated dienes $\left(\mathrm{A}_{232} \mathrm{~nm} / 1\right.$ serum$)$} & \multicolumn{2}{|l|}{ TBARS $(\mu \mathrm{M})$} & \multicolumn{2}{|l|}{$\underline{\mathrm{SOD}}(\mathrm{U} / \mathrm{g} \mathrm{Hb})$} \\
\hline & Before exercise & After exercise & Before exercise & After exercise & Before exercise & After exercise \\
\hline CD & $4,123 \pm 67^{\mathrm{a}}$ & $4,461 \pm 108^{\mathrm{a}}$ & $9.70 \pm 0.21^{\mathrm{a}}$ & $12.87 \pm 0.34^{\mathrm{a}}$ & $2,744 \pm 72^{\mathrm{a}}$ & $3,318 \pm 58^{\mathrm{a}}$ \\
\hline LD & $4,069 \pm 171^{\mathrm{a}}$ & $4,258 \pm 168^{\mathrm{a}, \mathrm{b}}$ & $9.41 \pm 0.16^{\mathrm{b}}$ & $11.34 \pm 0.30^{\mathrm{b}}$ & $2,258 \pm 58^{\mathrm{b}}$ & $2,604 \pm 71^{\mathrm{b}}$ \\
\hline HD & $4,038 \pm 211^{\mathrm{a}}$ & $4,200 \pm 197^{\mathrm{b}}$ & $8.00 \pm 0.23^{\mathrm{c}}$ & $9.03 \pm 0.21^{\mathrm{c}}$ & $2,599 \pm 84^{\mathrm{c}}$ & $2,738 \pm 87^{\mathrm{c}}$ \\
\hline
\end{tabular}

Values are mean \pm SD of ten rats per group. Values with different superscripts are significantly different at $p<0.05$

duced. TBARS has maximum absorption under a wavelength of $532 \mathrm{~nm}$, and it is positively correlated to MDA (Draper and Hadley 1990). Table 4 showed that the MDA values of the three groups were significantly different $(p<0.05)$ before and after swimming. Judging from the MDA rising ratio of each group, it was found that the treatment groups can effectively lower the production of MDA. Thus, it is evident that red mold rice possesses the ability of reducing lipid peroxide and suppressing tissue damage in response to exercise.

Superoxide dismutase Superoxide dismutase (SOD) is one of the most important enzymes in the antioxidant defense system. Table 4 showed the SOD analyzed; the SOD values of the three groups appeared to be significantly different before and after swimming $(p<0.05)$. However, the SOD concentration increase for each group after swimming varied very much in that the $\mathrm{CD}$ group increased by $20.92 \%$, the LD group increased by $15.32 \%$, and the HD group increased by $5.35 \%$.

\section{Discussion}

This study was designed to investigate the effects of red mold rice administration on endurance exercise in rats. The major findings are listed below:

Extends the swimming time for the rats and effectively delays the lowering of glucose in the blood This phenomenon indicated that the blood-glucose-regulating ability of the treatment groups was higher than that of the CD, and the blood glucose levels of the treatment groups in the endurance swimming did not decrease as much, therefore enhancing the swimming endurance of the treated rats. Hypoglycemia can suppress the active functioning of the brain during exercise, and this often led to the inability of continuing exercise. On the other hand, the homeostasis of blood glucose played an important role in prolonging endurance exercise (Ahlborg and Felig 1982; Van der Vusse and Saris 1991). It was known that endurance capacity was markedly decreased by the inhibition of gluconeogenesis (John-Alder et al. 1987), because gluconeogenesis played the major role of glucose homeostasis in endurance exercise (Donovan and Sumida 1990). In our study, the prolongation of the swimming times exhibited by the rats fed with red mold rice must be related to the improvement in the physiological function or metabolic control of exercise and the activation of energy metabolism.
Prevents the increase in lactate and BUN concentrations Blood lactate is the glycolysis product of carbohydrate under an anaerobic condition, and glycolysis is the main energy source for fierce exercise in a short time. Therefore, blood lactate is closely related to workload intensity and is one of the important indicators for judging the intensity of the exercise or the degree of fatigue. In other words, blood lactate represents the degree of fatigue after exercise and the condition of recovery. In this study, the data showed that oral administration of red mold rice can effectively delay the increasing of lactate in the blood. BUN is the metabolism outcome of protein and amino acid. Urea is formed in the liver and is carried by the blood to the kidneys for excretion. Because urea is separated from the bloodstream by the kidneys, urea nitrogen concentration in the blood can be used as the indication of renal function. However, there are many factors other than renal disease that can cause BUN alteration. This includes protein breakdown, dehydration, stress, fatigue, etc. The BUN value was found to increase significantly after exercise. $\mathrm{Wu}$ (1999) pointed out that the BUN in the blood rises significantly for a long-run athlete after exercise. His comment matches our findings in this research. In addition, $\mathrm{Wu}$ also pointed out that the transformation of BUN in the blood serum was closely related to exercise intensity and sustained time.

Hemoglobin on the endurance of exercise Hemoglobin, also called hemachrome, is the main component of erythrocyte. Its main function is to serve as the carrier for the erythrocyte to transport oxygen and partial carbon dioxide. Hemoglobin also has the effect on maintaining the body fluid's acid-alkali balance. Therefore, it can directly affect the substance metabolism and the energy metabolism in the body and, in turn, affect body function and exercise ability of the human body, the exercise's loading capacity, and fatigue. Hemoglobin normally is one of the indicators to reflect the degree of recovery from fatigue after exercise. Its value will be better if it is not too high because when the concentration of hemoglobin in the blood is too high, it will result in the increase in blood pressure and the sticky dense degree of the blood, which, in turn, slows down the blood flow and reduce the oxygen supply in the muscle tissue and cause damage to the body. In this study, the results showed that red mold rice can affect the concentration of the hemoglobin in the blood of a rat after exercise, and the concentration was significantly lower than that of the CD. 
Lipid peroxidation in the blood can be improved through the use of red mold rice Oxygen is used as the fuel for the metabolism process, and the usage of oxygen will be increased during exercise, which means an increase in turnover of ROS (Sen 1995). The production of ROS is harmful to the mitochondria in the cell because ROS will affect the function of mitochondria, causing it to lose the efficacy of electron transport chain, which also leads to aging or fatigue. This type of oxidized injury to mitochondria would result in lipid peroxidation and cause cell damage (Nicolson 2001). The metabolite produced during the lipid peroxidation process can be used as the method to judge oxidized injury (Halliwell and Gutteridge 1995). For example, the formation of DC provided early indication of lipid peroxidation, the formation of an end product during the lipid peroxidation process such as aldehydes, and the increase in SOD concentration; all can be used to judge the degree of lipid peroxidation. Margaritis et al. (2003) pointed out that during tapering exercise, antioxidant supplementation at nutritional doses reinforced antioxidant status response to the effect of exercise-induced oxidative stress.

The antioxidant activity of red mold rice was suggested by Anyia et al. (1999); the study shows that Monascus species produces a different antioxidant activity from different Monascus species. Ordinary red mold rice showed the 1,1-diphenyl-2-picrylhydrazyl (DPPH) scavenging action; the red mold rice that can scavenge the DPPH radical inhibited lipid peroxidation and experimentally induced liver injuries of rats. Anyia et al. (1999) further purified red mold rice extracts to find out that the antioxidant ingredient was dimerumic acid. Besides, $\mathrm{Wu}$ and $\mathrm{Wu}(2000)$ pointed out in the research that the substances produced from Monascus species has the ability to scavenge DPPH and further use ethyl acetate to extract a fermentation substance and use high-pressure liquid chromatography (HPLC) to isolate and purify the substances, and determined the chemical structure of the product by using ${ }^{1} \mathrm{H}$-NMR and ${ }^{13} \mathrm{C}$-NMR methods. The result showed that 3-hydro-4-methoxy-benzoic acid possessed antioxidant ability. Also, we verified that red mold rice possessed DPPH scavenging activity, suppressing the formation of DC, superoxide anion scavenging activity, and chelating activity on ferrous ions in our previous research (Wang et al., unpublished data). In addition, the enzyme scavenges superoxide $\left(\mathrm{O}_{2} \cdot{ }^{2-}\right)$, which is an electron reduction product of oxygen. Current literature indicated that endurance training could enhance the antioxidant enzyme capacity in skeletal muscle (Lawler et al. 1994; Ji 1999). An acute bout of exercise has been proven to be able to increase SOD activity in a number of tissues, including the liver (Ji et al. 1990; Ji and $\mathrm{Fu}$ 1992), skeletal muscle (Ji et al. 1990), and heart (Ji and Mitchell 1994). The SOD activity increase may be the result of a self-protective mechanism which was developed from superoxide-generated radicals operating in aging or fatigue. Chance and Boveris (1979) once addressed that when the antioxidant enzyme within the body has clearly risen, it can infer that the output of free radical is clearly increased. Their comment matches the result found in this research.

Amino acid on the endurance of exercise Normally, muscle exercise would need a large quantity of energy which came from glycogen and fatty acid. Contrary to glucose and fatty acid, an amino acid would release ammonia throughout metabolism (Devlin et al. 1990). The role that amino acid plays in the muscular activity is regulating metabolism rather than supplying the energy. However, when metabolism is badly in need of glucose to serve as an energy source, gluconeogenesis will occur. That is, amino acid will render to the formation of oxalacetate, which is the medium product between pyruvic acid and a tricarboxylic acid cycle. Oxalacetate will eventually be converted to glucose to save the consumption of a carbohydrate source and prevent a sharp decrease of blood glucose after exercise. Supplying amino acid, especially the branched chain amino acids, can improve exercise ability and markedly retard the catabolism of protein in the muscle during exercise (Blomstrand and Newsholme 1992). Bazzarva et al. (1992) pointed out that the amount of amino acids, especially for alanine, glycine, valine, GABA, isoleucine, threonine, serine, and tyrosine, in the plasma will decrease rapidly during the endurance test. Among the amino acids mentioned above, red mold rice contains alanine, valine, GABA, and serine. This implied that the amino group in the red mold rice can enhance exercise ability. In addition, red mold rice also contains GABA and glutamic acid, which have a very positive effect on the nervous system and will be helpful for the exercise to be executed (Guezennec et al.1998). Marquezi et al. (2003) pointed out that aspartic acid is helpful in the oxidative deamination and can lower the blood ammonia concentration, therefore delaying fatigue occurrence.

In summary, red mold rice is a secondary metabolite of Monascus spp. and was widely used as a health food. Other than the effect of lowering cholesterol and blood pressure, red mold rice was also found to possess an antifatigue effect, extend the swimming time for the rats, effectively delay the lowering of glucose in the blood, and prevent the increase in lactate and BUN concentrations. In addition, the result suggested that the red mold rice supplementation may decrease the contribution of exercise-induced oxidative stress.

\section{References}

Abe T, Takiguchi Y, Tamura M, Shimura J, Yamazaki KI (1995) Effect of vespa amino acid mixture (VAAM) isolated from hornet larval saliva and modified VMM nutrients on endurance exercise in swimming mice improvement in performance and changes of blood lactate and glucose. Jpn J Physiol Fitness Sports Med 44:225-238

Ahlborg C, Felig P (1982) Lactate and glucose exchange across the forearm legs and splanchnic bed during and after prolonged leg exercise. J Clin Invest 69:45-54

Alessio HM, Goldfarb AH (1988) Lipid peroxidation and scavenger enzymes during exercise: adaptive response to training. J Appl Physiol 64:1333-1336 
Anyia Y, Yokomakura T, Yonamine M, Shimada K, Nagamine T, Shimabukuro M, Gibo H (1999) Screening of antioxidant action of various molds and protection of Monascus anka against experimentally induced liver injuries of rats. Gen Pharmacol 32:225-231

Anyia Y, Ohani II, Higa T, Miyagi C, Gibo H, Shimabukuro M, Nakanish H, Taira J (2000) Dimerumic acid as an antioxidant of the mold: Monascus anka. Free Radic Biol Med 28:999-1004

Armstrong RB (1990) Initial events in exercise-induced muscular injury. Med Sci Sports Exerc 22:429-435

Bazzarva TL, Murdoch DD, Wu SL, Herr DC, Snider IP (1992) Plasma amino acid responses of trained athletes to two successive exhaustion trials with and without interim carbohyrate feeding. Am Coll Nutr 11:501-511

Bird P, Draper H (1984) Comparative studies on different methods of malonaldehyde determination. Methods Enzymol 105:299305

Blanc PJ, Loret MO, Santerre AT, Pareilleux A, Prome D, Prome JC, Laussac JP, Goma G (1994) Pigment of Monascus. J Food Sci 59:862-865

Blomstrand B, Newsholme EA (1992) Effect of branched chain amino acid supplementation on the exercise induced change in aromatic amino acid concentration in human muscle. Acta Physiol Scand 146:293-298

Chance BH, Boveris A (1979) Hydroperoxide metabolism in mammalian organs. Physiol Rev 59:527-605

Cho SH, Choi YS (1994) Lipid peroxidation and antioxidant status is affected by different vitamin E levels when feeding fish oil. Lipids 29:47-52

Corongiu F, Lai M, Milai A (1983) Carbon tetrachloride, bromotrichloromethane and ethanol acute intoxication. J Biochem 212:625-631

Davies KJA, Quintanilha AT, Brooks GA, Packer L (1982) Free radicals and tissue damage produced by exercise. Biochem Biophys Res Commun 10:1198-1200

Devlin JT, Brodsky I, Scrimgeour A, Fuller S, Bier DM (1990) Amino acid metabolism after intense exercise. Am J Physiol 258:249-255

Donovan CM, Sumida KB (1990) Training improves glucose homeostasis in rats during exercise via glucose production. Am J Physiol 258:770-776

Draper HH, Hadley M (1990) Malondialdehyde determination as index of lipid peroxidation. Methods Enzymol 186:421-431

Endo A (1979) Monacolin K, a new hypercholesterolemic agent produced by a Monascus species. J Antibiot 32:852-854

Gobatto CA, Rostom de Mell MA, Sibuya CY, Moreira de Azevedo JR (2001) Maximal lactate steady state in rats submitted to swimming exercise. Comp Biochem Physiol 130:21-27

Guezennec CY, Abdelmalki A, Serrurier B (1998) Effect of prolonged exercise on brain ammonia and amino acids. Int J Sports Med 19:323-327

Halliwell B, Gutteridge JMC (1995) Lipid peroxidation: a radical chain reaction. In: Free radicals in biology and medicine. Oxford University Press, London, pp 188-218

Jeon SM, Bok SH, Jang MK, Lee MK, Nam KT, Park YB, Rhee SJ, Choi MS (2001) Antioxidative activity of naringin and lovastatin in high cholesterol-fed rabbits. Life Sci 69:2855-2866

Ji LL (1999) Antioxidants and oxidative stress in exercise. Proc Soc Exp Biol Med 222:283-292

Ji LL, Fu RG (1992) Responses of glutathione system and oxidant enzymes to exhaustive exercise and hydroperoxide. J Appl Physiol 72:549-554

Ji LL, Mitchell EW (1994) Effects of adriamycin on heart mitochondrial function in rested and exercised rats. Biochem Pharmacol 47:877-885

Ji LL, Dillon D, Wu E (1990) Alteration of antioxidant enzymes with aging in rats skeletal muscle and liver. Am J Physiol 258:918-923
John-Alder HB, McAllister RM, Teriung RL (1987) Reduced running endurance in gluconeogenesis inhibited rats. Am J Physiol 251:137-142

Juzlova P, Martinkov L, Kren V (1996) Secondary metabolites of the fungus Monascus; a review. J Ind Microbiol 16:163-170

Kanter MM (1994) Free radicals, exercise, and antioxidant supplementation. Int J Sport Nutr 4:205-220

Kono I, Himeno K (2000) Changes in $\gamma$-aminobutyric acid content during beni-koli making. Biosci Biotechnol Biochem 64:617619

Lawler JM, Powers SK, Dijk H, Visser T, Kordus MJ, Ji LL (1994) Metabolic and antioxidant enzyme activities in the diaphragm: effects of acute exercise. Respir Physiol 96:139-149

Lucas J, Schumacker J, Kunz B (1993) Solid state fermentation of rice by Monascus purpureus. J Korean Soc Food Sci 9:149-159

Margaritis I, Palazzetti S, Rousseau AS, Richard MJ, Favier A (2003) Antioxidant supplementation and tapering exercise improve exercise-induced antioxidant response. J Am Coll Nutr 22:147-156

Marquezi ML, Roschel HA, Costa ADS, Sawada LA, Lancha AH Jr (2003) Effect of aspartate and asparagine supplementation on fatigue determinants in intense exercise. Int J Sport Nutr Exerc Metab 13:65-75

Martinkova L, Juzlova P, Vesely D (1995) Biological activity of polyketide pigment production by fungus Monascus. J Appl Bacteriol 79:609-616

Martinkova L, Juzlova P, Kren V, Kucerouva Z, Havlicek V, Olsovsky P, Hovorka O, Rihova B, Vesly D, Vesela D, Ulrichova J, Prikrylova V (1999) Biological activities of oligoketide pigments of Monascus purpureus. Food Addit Contam 16:15-24

Nicolson GL (2001) Lipid replacement as an adjunct to therapy for chronic fatigue, anti-aging and restoration of mitochondrial function. J Am Nutraceut Ass 4:11-19

Paglia DE, Valentine JP (1967) Studies in the quantitative characterization of erythrocyte glutathion peroxidase. J Lab Clin Med 70:158-169

Putman CT, Spriet LL, Hultman E, Lindinger MI, Lands LC, McKelvie S, Cederbland C, Jones NL, Heigenhauser CJF (1993) Pyruvate dehydrogenase activity and acetyl group accumulation during exercise after different diets. Am J Physiol 265:752-760

Sen CK (1995) Oxygen toxicity and antioxidants. Indian J Physiol Pharmacol 39:177-196

Su YC, Huang JH (1976) Studies on the production of ankapigment. J Chin Agric Chem Soc 14:45-58

Van der Vusse PB, Saris CJ (1991) Carbohydrate supplementation glycogen depletion and amino acid metabolism during exercise Am J Physiol 260:883-890

Wang JJ, Pan TM (2003) Effect of red mold rice supplements on serum and egg yolk cholesterol levels of laying hens. J Agric Food Chem 51:4824-4829

Wong HC, Koehler PE (1981) Production and isolation of an antibiotic from Monascus purpureus and its relationship to pigment production. J Food Sci 46:589-592

Wu IT (1999) The effects of serum biochemical value with different beverage to replenish and intermittent exercise in high intensity. Tahan Junior College Engineering Business J 13:387-400

Wu GF, Wu XC (2000) Screening DPPH radical scavengers from Monascus sp. Acta Microbiol Sin 40:394-399

Yasukawa K, Takahashi M, Natori S, Yamazaki M, Takeuchi M, Takido M (1994) Azaphilones inhibit tumor promotion by 12$o$-tetradecanoyl-phorbol-13-acetate. Oncology 45:108-112

Zhou Q, Kummerow FA (2000) Antioxidative effects of lovastatin in cultured human endothelial cells. J Nutr Biochem 13:200 208 